\title{
An Empirical Study of Alxa League Energy Consumption and Environmental Pollution in China
}

\author{
Peilin $\mathrm{Li}^{1}$, Jialin $\mathrm{Liu}^{1} \&$ Haiying $\mathrm{Ma}^{1}$ \\ ${ }^{1}$ School of Economics, Northwest University for Nationalities, Lanzhou, China \\ Correspondence: Haiying Ma, Associate professor, School of Economics, Northwest University for Nationalities, \\ Lanzhou 730124, China. E-mail: lxmahaiying8888@163.com
}

Received: June 20, 2015

Accepted: July 5, 2015

Online Published: August 5, 2015

doi:10.5430/jms.v6n3p21

URL: http://dx.doi.org/10.5430/jms.v6n3p21

\begin{abstract}
Because of the continual increase of the energy consumption and the long-standing patterns of extensive consumption about energy in Alxa, it is significance to the problem of environmental pollution. Alxa is main neighborhoods for Mongolian in northwest China, where the ecological environment is quite fragile and environmental pollution has had a negative impact on local desert ecological environment and economic continual development. Since 1980, the fragile environment increasingly become one of the major obstacles to continued economic development of Alxa; In particular, the severity of environmental problems that become the focus of Alxaess and Chinese has affected the industrial development Alxa in 2014. Firstly, the paper reads energy consumption leads to environmental pollution. Secondly, it depicts the causes of the problem from the Amounts of energy consumption and industrial structure. Finally, the suggestion, including Optimized energy consumption structure, modify the industrial structure, Introduced Market Mechanism and so on, is made to solve the environmental problems in Alxa League.
\end{abstract}

Keywords: energy consumption, environmental pollution, Alxa League

\section{Introduction}

Alxa League is located in northwest China with a total area of 27 square kilometers. Alxa where the ecological environment is quite fragile is main neighborhoods for Mongolian in northwest China. Since 1980, with the rapid development of economy and society, the amount of energy consumption is growing rapidly in Alxa League League. For example, there is $2,545,100$ tons of total energy consumption in 2005, the growth to 5,240,500 tons in 2010, an increase of nearly 5 years, more than tripled. At the same time, environmental pollution has had a negative impact on local desert ecological environment. For instance, that the waste water in Tengger industrial park was discharged illegally lead to serious desert groundwater pollution in 2014, resulting in huge economic losses.

Because of the fragile desert ecosystem environment in Alxa, Exacerbate environmental pollution has devastating damage on the ecological environment. So, it is need to Analyze and investigate the relationship between energy consumption and Alxa League League between environmental pollution for the policy measures such as promoting industrial restructure actively, optimizing energy structure, encouraging the implementation of energy conservation, improving energy efficiency, etc., which makes sense for having efforts to reduce the emissions of greenhouse gas and achieve the targets of energy reduction.

But so far, Chinese domestic research combine energy consumption with environment pollution, only focused on one of them. After 2009, China witnesses the study about energy consumption with environment pollution. Wang Lina - analyzed consumption of coal and industrial pollution chosen from Study on Determinants of Chian's Energy Efficiency and Environment in Energy-Intensive and Poiiuting Industries, and draws a conclusion that there is proportionality between energy-consumption and environmental pollutions.

Those essays above are analyzed by a method of metrocogical analysis according to the data. The advantage is that it can contribute to a quantitive analysis of the ralated function, direction and big or small, and between energy consumpution and environmental pollutions, but which cannot make a co-integration analysis sise.

Song Xingda - his research on The Empirical Research of China's Carbon Dioxide Emissions and Eergy Effciency Issues, the multiplier method and learned that energy consuption has a long-term and short-term influence on 
consuption for Carbon Dioxide. There essay mainly used multipieror non-multipier.According to production factions, the advantage of multipieror method is that it ca effectively distinguish the influence of random factors, but an unavoidable disadvantage is it aquires a certain number of sample size.

This paper is based on quantitative and qualitative analysis method of combining study. Alxa League energy consumption and sulfur dioxide emissions were analyzed by means of using multiple linear regression analysis are measured, and then use ARMA model to forecast sulfur dioxide emissions in Alxa League. Firstly, the paper reads energy consumption and the current situation environmental pollution in Alxa League. Secondly, the reasons that the increasing environmental pollution caused by energy consumption in Alxa League are analysed. Last, recommendations are made to solve the problem, such as optimizing energy consumption structure, modifying the industrial structure.

\section{Alxa League Status of Energy Consumption and Environmental Pollution}

\subsection{Alxa League Status of Energy Consumption}

The amount of energy consumption in Alxa League has a significant growth in the past 20 years. For example, energy consumption in Alxa League was 2,545,100 tons in 2005, an increase of nearly 5 years, more than twice, growing to 5,240,500 tons by 2010. Substantial growth of energy consumption is the result of the growth of Alxa rapid economic between 30 years. Alxa League's GDP was 56 million yuan in 1980, an increase of 792 times between 30 years, and reached 44.351 billion; the per capita GDP was 185724.46 yuan in 2013, equivalent to $\$ 29,988.45$, which per capita GDP has reached the level of developed countries. Alxa League's per capita GDP in 2013 ranked third in all-Chinese urban's.

With the rapid development of economy, the demand of energy consumption is increasing in Alxa League. Alashan region which has own to abundant coal resources, in order to satisfy the need of their own economic development and the rapid development of the local coal mining industry, has always been locally produced coal. Alxa League's total production is only 270,000 tons of raw coal in 1981, an increase of 30 years and 58 times has reached 15.474 million tons in 2012. Overall, with the rapid economic growth in Alxa League nearly 30 years, there is a substantial increase in energy consumption.

\subsection{Alxa League Environmental Pollution Situations}

That the waste water in Tengger industrial park was discharged illegally lead to serious desert groundwater pollution in 2014, harmed to livestock and local economic development. Desert groundwater was completely contaminated, which will seriously threaten the survival of local herders and the development of livestock. At the same time it would undermine China's fourth largest desert-the Tengger Desert in unique ecological environment, resulting in more severe desertification. Restoration of desertified land in the economic costs would cause huge economic impact on the Alxa League.

Alxa League is the birthplace of the world's major storms. Sandstorm has some negative effects, such as soil erosion, destruction of vegetation, buried farmland, affecting the flight, buried embankment, blocking traffic. According to the Civil Affairs Bureau of Alxa League's statistics between 1985 and 2006, sandstorm causes crop harvest area 56,130 square kilometers, the death of large livestock 45.28 million, 178.3 million yuan in direct economic losses. Especially 2 sandstorms caused a direct economic loss of 9.69 million yuan in 2005 .

Alxa League's sulfur dioxide emissions is 5,090 tons in 2001, to 68,418 tons in 2014, which is 13.44 times the 2001 average of 14 years and an increase of $22 \%$ per year. Along this trend, sulfur dioxide emissions in the future even increasing, this will inevitably result in irreparable damage to the fragile ecological environment of Alxa League. In the long run, it will definitely affect the local economy sustained.

\section{Alxa League Environmental Pollution Cause Analysis and Forecast}

\subsection{Centralized Fossil Energy Consumption Resulting in Increased Pressure on the Environment}

Because pollution is caused by a variety of factors, for simple analysis, we are chosen five major factors to analyze. Selecting the 2000-2014 Alxa League energy consumption (mainly coal), Alxa League of gross production, coal production, sewage emissions, the number of new jobs in the tertiary industry and the data of sulfur dioxide emissions, multiples linear regression analysis. Energy consumption is set to Ec, gross GDP representing producers, $\mathrm{CP}$ representative of coal production, $\mathrm{PW}$ on behalf of sewage discharge and ITE representatives of the number of new jobs in the tertiary industry. The CP and PW data exist unit root through unit root test, which indicats that the data is not stable, so the need for differential smooth data to get a regression analysis. 


\begin{tabular}{|c|c|c|c|c|c|c|c|c|c|}
\hline & & \multicolumn{2}{|c|}{ IICP } & \multicolumn{2}{|c|}{$\mathrm{CP}$} & \multicolumn{2}{|c|}{ IIPW } & \multicolumn{2}{|c|}{ PW } \\
\hline \multirow{2}{*}{\multicolumn{2}{|c|}{$\begin{array}{c}\text { Augmented } \\
\text { Dickey-Fuller test } \\
\text { statistic }\end{array}$}} & t-Statistic & Prob.* & $\mathrm{t}$-Statistic & Prob.* & t-Statistic & Prob.* & t-Statistic & Prob.* \\
\hline & & -3.66412 & 0.0778 & -2.61661 & 0.2817 & -4.14792 & 0.0374 & -2.36461 & 0.3786 \\
\hline \multirow{3}{*}{$\begin{array}{l}\text { Test } \\
\text { critical } \\
\text { values: }\end{array}$} & $1 \%$ level & -5.29584 & & -4.88626 & & -5.12475 & & -4.80008 & \\
\hline & $5 \%$ level & -4.08157 & & $\overline{-3.82975}$ & & -3.93364 & & -3.791172 & \\
\hline & $\begin{array}{l}10 \% \\
\text { level }\end{array}$ & -3.46791 & & -3.36284 & & -3.42003 & & -3.34253 & \\
\hline
\end{tabular}

From the results, we can see that $\mathrm{CP}$ and PW exist no unit root at the $10 \%$ level does after twice difference. Then the data is stable and can be regression results of Analysis.

\begin{tabular}{ccccc}
\hline Variable & Coefficient & Std. Error & t-Statistic & Prob. \\
\hline C & -5496.947 & 29520.44 & -0.18628 & 0.8576 \\
EC & 199.2239 & 105.1380 & 1.894880 & 0.1000 \\
GDP & -0.705211 & 1.199685 & -0.58783 & 0.5751 \\
IICP & -0.022889 & 14.08005 & -0.01626 & 0.9987 \\
IIPW & 19.41983 & 27.63558 & 0.702711 & 0.5049 \\
ITE & -6.235390 & 9.555040 & -0.65276 & 0.5349
\end{tabular}

Adjusted

R-squared 0.836167

Representative of the overall fit better.

However, the ${ }^{t\left(\hat{\beta}_{\mathrm{cp}}\right)}$ do not pass the test, ${ }^{t\left(\hat{\beta}_{\mathrm{cp}}\right)}$ does not pass T inspection, at the same timeso do $t\left(\hat{\beta}_{\mathrm{GDP}}\right), t\left(\hat{\beta}_{\mathrm{Ec}}\right)$, $t\left(\hat{\beta}_{\mathrm{IIPW}}\right), t\left(\hat{\beta}_{\mathrm{ITE}}\right)$ and ${ }^{t\left(\hat{\beta}_{\mathrm{EC}}\right)}$. The results of the analysis may exist multiple collinear, so the use of backward stepwise regression method be handled. $\mathrm{p}$-value forwards $=0.05$, $\mathrm{p}$-value backwards $=0.07$, selected $\mathrm{p}$-value forwards $=0.05$, $\mathrm{p}$-value backwards $=0.07$ and Results of treatment): Stopping criterion: $\mathrm{p}$-value forwards/backwards $=0.05 / 0.07$.

\begin{tabular}{crrrr}
\hline Variable & Coefficient & Std. Error & t-Statistic & Prob.* \\
\hline EC & 135.8241 & 15.18656 & 8.943706 & 0.0000 \\
ITE & -4.450368 & 2.184002 & -2.037712 & 0.0664 \\
& & & & \\
Adjusted R-squared & 0.881279 & & & \\
\hline
\end{tabular}

$\overline{R^{2}}=0.881279$, Representative of the overall fit better. the standard error of $\hat{\beta}_{E \mathrm{c}}$ is $t\left(\hat{\beta}_{E \mathrm{c}}\right)=8.943706$, because 


$$
t\left(\hat{\beta}_{E C}\right)=8.943706>t_{0.025}(15)=2.131
$$

pass T test, so does $t\left(\hat{\beta}_{\text {ITE }}\right)$, which proves that model Updating is successful. Also it shows that energy consumption have a significant relationship with environmental pollution between 2000 and 2014 in Alxa League. From the results obtained.

$$
\mathrm{SO}_{2}=135.8241 \mathrm{EC}-4.450368 \mathrm{ITE}
$$

When other conditions remain unchanged, Alxa League energy consumption for every 10,000 tons of sulfur dioxide will lead to increased emissions of Alxa League 135.8241 tons. When other conditions remain unchanged, the tertiary industry Alashan number of new jobs increased by per person will reduce sulfur dioxide emissions by 44,500 tons.

As can be seen from the analysis, there is a high positive correlation between energy consumption and sulfur dioxide emissions in Alxa League; energy consumption will result in the increase in sulfur dioxide emissions in Alxa League; the number of tertiary industry of new jobs and sulfur dioxide emissions negatively correlated; Tertiary industry increased number of new jobs will reduce sulfur dioxide emissions.

Coal-based energy consumption EC and the tertiary sector of new jobs ITE have impacts on sulfur dioxide emissions. Single energy consumption increased sulfur dioxide emissions, high-tech industry of new jobs to reduce essions of sulfur dioxide. Description single coal-based energy consumption patterns of increased environmental pollution, development of tertiary industry will reduce environmental pollution.

\subsection{Alxa League Environmental Pollution Forecast}

The data of Alxa sulfur dioxide emissions from the first quarter of 2000 to the first quarter of 2015 is selected to forecast. We can see in auto-correlation digram which taken first-order differential Log on the initial data.

Based on the diagram of the sulfur dioxide original sequence after take the logarithm of first difference autocorrelation figure can be seen that the sulfur dioxide original sequence has had the trend to eliminate autocorrelation ananlysis diagram, but it can also seen that step for four seasons difference because every four

\begin{tabular}{|c|c|c|c|c|c|c|c|c|c|}
\hline \multicolumn{2}{|c|}{ Autocorrelation } & \multicolumn{3}{|c|}{ Partial Correlation } & \multicolumn{2}{|c|}{ Autocorrelation } & \multicolumn{3}{|c|}{ Partial Correlation } \\
\hline 1 & $\square$ & 1 & $\square$ & 1 & 면 & t & $\square$ & 3 & 1 \\
\hline 1 & 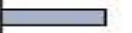 & 1 & $\square$ & 2 & $1 \mathrm{C}$ & I & 1 둔 & 1 & 2 \\
\hline 1 & 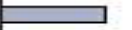 & 1 & $\square$ & 3 & 1 당 & t & $\square$ & 1 & 3 \\
\hline 1 & $\square$ & 1 & $\square$ & 4 & 1 & 马 & 1 & 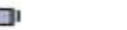 & 4 \\
\hline 1 & 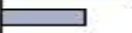 & $\square$ & 1 & 5 & 담 & I & 1 미 & 1 & 5 \\
\hline 1 & 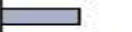 & 1 口 & 1 & 6 & 1 의 & I & 1 무 & 1 & 6 \\
\hline 1 & $\square$ & 1 & 1 & 7 & 1 맘 & $t$ & 口 & 1 & 7 \\
\hline 1 & 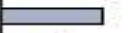 & 1 & $\square$ & 8 & 1 & $\square$ & 1 & יבן & 8 \\
\hline 1 & 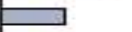 & 1 & 1 & 9 & 10 & I & 1 다 & 1 & 9 \\
\hline 1 & $\square$ & 1 두 & 1 & 10 & 1 다 & I & 1 이 & 1 & 10 \\
\hline 1 & $\square$ & 1 口 & 1 & 11 & 14 & i & 1 미 & 1 & 11 \\
\hline 1 & $\square$ & 1 & 1 & 12 & 1 & $\square$ & & 1 & 12 \\
\hline I & $\square$ & 15 & 1 & 13 & $1 \square$ & I & 1 다 & 1 & 13 \\
\hline 1 & 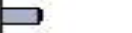 & 14 & 1 & 14 & 1 요 & 1 & 1 며 & 1 & 14 \\
\hline 1 & $\square$ & 1 다 & 1 & 15 & 1 무 & I & 1 다 & 1 & 15 \\
\hline
\end{tabular}
months a seasonal cycle.

Figure 1. The diagram of the sulfur dioxide original sequence and the $\mathrm{ILSO}_{2}$ autocorrelation analysis $\mathrm{ILSO}_{2}$ 


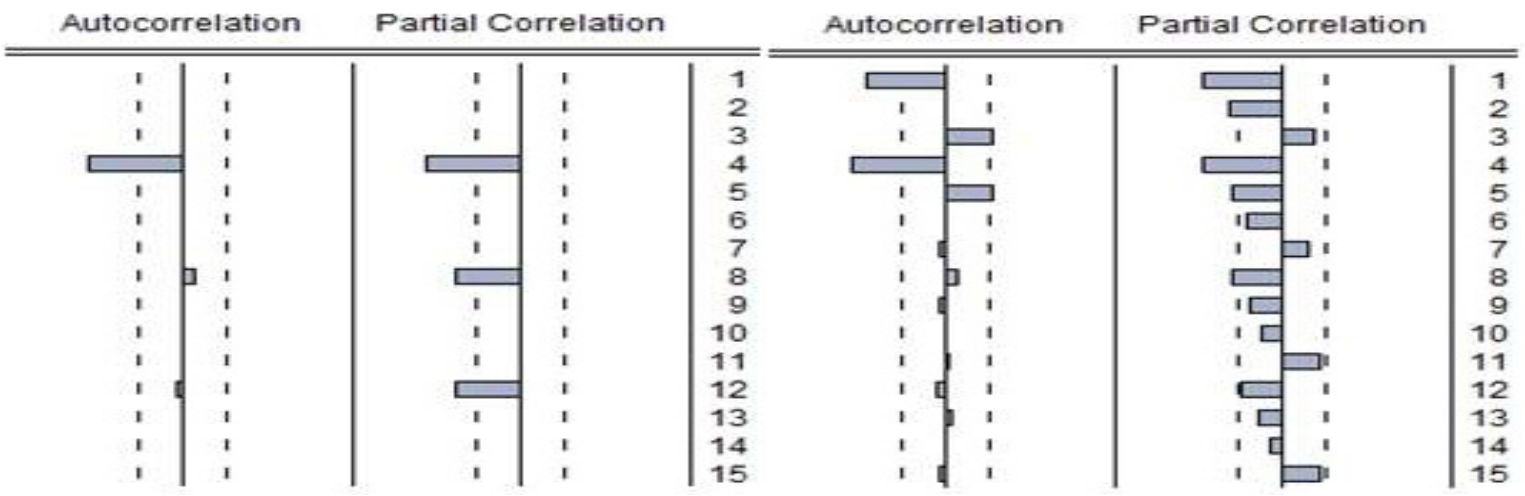

Figure 2. The diagram of the $\mathrm{SILSO}_{2}$ original sequence and the $\mathrm{ILSO}_{2}$ a utocorrelation analysis $\mathrm{ISILSO}_{2}$

From the seasonal difference after the first order and second-order autocorrelation can be seen, the first-order differential season seasonally basically eliminated, but did not completely eliminate second-order seasonal, so using A sequence autocorrelogram determines value of $\mathrm{p}, \mathrm{q}$.

Series trend is eliminated after an order by Differential, so $\mathrm{d}=1$; due to the first-order differential season, seasonal basically is eliminated, so $\mathrm{D}=1$. Considering the $(\mathrm{p}, \mathrm{q})$ combination has $(1,1),(2,1),(3.1))$

Table 1. Model selection and evaluation and the parameters

\begin{tabular}{|c|c|c|c|c|c|c|}
\hline$(\mathrm{p}, \mathrm{q})$ & $\phi_{1}$ & $\phi_{2}$ & $\phi_{3}$ & $\theta_{1}$ & $\Phi_{1}$ & $\Theta_{1}$ \\
\hline$(1,1)$ & $-6.15 \mathrm{E}-05$ & - & - & -0.37379 & 0.000148 & -0.92096 \\
\hline$(2,1)$ & $-6.14 \mathrm{E}-05$ & $8.73 \mathrm{E}-05$ & - & -0.37379 & 0.000148 & -0.92096 \\
\hline$(3,1)$ & -0.00031 & $8.74 \mathrm{E}-05$ & 0.00014 & -0.37379 & 0.000397 & -0.92096 \\
\hline$(p, q)$ & \multicolumn{2}{|c|}{ Adjusted $\mathrm{R}^{\wedge} 2$} & \multicolumn{2}{|c|}{ AIC } & \multicolumn{2}{|c|}{$\mathrm{SC}$} \\
\hline$(1,1)$ & \multicolumn{2}{|c|}{0.622850} & \multicolumn{2}{|c|}{1.884902} & \multicolumn{2}{|c|}{2.036418} \\
\hline$(2,1)$ & \multicolumn{2}{|c|}{0.613960} & \multicolumn{2}{|c|}{1.947842} & \multicolumn{2}{|c|}{2.139044} \\
\hline$(3,1)$ & \multicolumn{2}{|c|}{0.604243} & \multicolumn{2}{|c|}{2.012942} & \multicolumn{2}{|c|}{2.244594} \\
\hline
\end{tabular}

By comparison, from these three ARIMA model $(2,1)$ and $(3,1)$ Adjusted $\mathrm{R}^{\wedge} 2$ is a little smaller, but value AIC,SC is bigger than $(1,1)$. Though the value of Adjusted $\mathrm{R}^{\wedge} 2$ in $(1,1)$ is smaller, AIC,SC is significantly smaller. At the same time, because of the principle that predication modal should be beneficial to practical operation, thus we use 91,1 ) from ARIMA to predicate.

$$
\mathrm{SO} 2_{\mathrm{t}}=-0.0000615 \mathrm{SO} 2_{\mathrm{t}-1}+U_{\mathrm{t}}-0.37379 \mathrm{U}_{\mathrm{t}-1}
$$

By selected ARIMA model, we predicted the sulfur dioxide emissions each quarter over the next decade.

Table 2. The predicted value of sulfur dioxide

10,000 ton

\begin{tabular}{ccccccc}
\hline 2015Q2-2016Q3 & 1768.322 & 885.9698 & 2220.994 & 1947.763 & 1752.097 & 877.8404 \\
2016Q4-2018Q1 & 2200.615 & 1929.89 & 1736.018 & 869.7849 & 2180.421 & 1912.181 \\
2018Q2-2019Q3 & 1720.088 & 861.8036 & 2160.413 & 1894.634 & 1704.304 & 853.8954 \\
2019Q4-2021Q1 & 2140.588 & 1877.248 & 1688.665 & 846.0598 & 2120.946 & 1860.022 \\
\hline
\end{tabular}


By predicting the results we can know Alxa sulfur dioxide emissions are maintained at least more than 60 million tons annually in the long term, for Chinese municipal units, the only sulfur dioxide emissions are a large environmental pressure. At the same time, sulfur dioxide emissions only is been as a representative study of environmental pollution this article, and other factors have a greater pressure on the local environment, such as waste water, industrial waste, etc. That it can count only annual economic loss caused by environmental pollution are showing rapid upward trend.

\section{The Measures of Alxa League in Energy Consumption Caused by Environmental Pollution}

\subsection{Optimizing Energy Consumption Structure}

Increase the Alxa League's share of gas consumption. West-East gas pipeline project three lines the western part of the infrastructure projects by the Yili Kazak Autonomous Prefecture Horgos to Zhongwei City, Ningxia is approved by the State Building. Alxa League can actively participate in the construction of the West-East Gas Pipeline Project and Zhongwei City of Ningxia Hui Autonomous Region, through bilateral cooperation and mutually beneficial trade in energy, not only help to improve the energy consumption structure, but also conducive to strengthening economic and trade cooperation with Northwest Alxa League in other regions and other areas of cooperation.

\subsection{Spreading Clean Coal Technology}

Taking account into the endowments of the energy resource Alxa League, a significant reduction in the proportion of coal in energy consumption is neither realistic nor economic in the short term. Alxa League must accelerate the development and promotion and use of clean coal technology, which both to reduce sulfur dioxide and soot emissions while meeting the energy production and the impact on the environment, but also can improve the utilization of coal, and give full play to China economic coal resources and reduce dependence on external energy sources.

\subsection{Optimize the Industrial Structure}

Alxa League is firstly to develop advanced manufacturing of high-tech industries and modern services, and trengthen basic industries, such as transportation energy and water conservancy, and infrastructure construction to promote national economic and social information. The key to improving technology intensive industry is to fully enhance the capability of independent innovation, to master the core technology in some important industries. There should be a group with independent intellectual property rights of technology innovation enterprises, increase in employment in the tertiary industry.

While, it is important to increasing the energy industry restructuring, efforts to transform the economic growth mode, speed up industrial restructuring and upgrading, take practical measures to focus on industry, especially high energy-consuming industries of energy saving, the light of the economic structure to promote and energy conservation, and actively develop low energy consumption intensity of the tertiary industry. Finally, coercive measures should be taken in order to limit the development of high-energy, high-polluting enterprises.

\subsection{Introduction of Market Mechanisms, and Guide Enterprises Low-carbon Production}

Only the joint action of visible hand and the invisible hand to promote the sound development of economy and society, Visible hand can effectively control energy consumption and carbon emissions in the short time, but only by relying on the invisible hand economic and social will transformly spontaneously. Because businesses need to make more profit, as long as they create a favorable market mechanisms, such as such a mechanism is capable of above-average level of energy saving enterprises with more than will get reward, lower than the average level of energy saving for the following enterprise will recieve punishment. It will automatically increase the development and utilization of energy saving technology. The similar systems include financial subsidies, carbon taxes, carbon trading market, pollution emissions trading markets.

\section{References}

Chen, J. (2010, October 1). Economic Development Pattern Transformation and Economic Structural Adjustment. (1st ed.). Economic managenment Press, 103.

Gao, J., Liang, G., \& Huang, Y. (2008, January). Energy Trade and China's Energy Security. Science Technology and Industry, 8(1), 96.

Hu, W. (2010, October). Development and Utilization of Non-conventional Natural Gas Resources in China. Journal of Daqing Petroleum Institute, 34(5), 12.

Huang, B. (2006, August). Conntermeasures for Promoting Industrial Structure Adjustment and Upgrading of China. 
Times Finance, 2, 22.

Li, M. (2011, June). Analysis and Prediction on Energy Consumption and CO2 E missio s of Industrial Sector in China. Dalian University of Technology.

Song, X. (2010, December). The Empirical Research of China's Carbon Dioxide Emissions and Eergy Effciency Issues. Jiangxi University of Finance Economics, 2, 4.

Wang, L. (2010, May). Study on Determinants of Chian's Energy Effciency and Enviroment in Energy-Intensive and Poiiuting Industries. Ocean Universityof Alxa League.

Zhang, J. (2010). Carbon Emissions and Economic Growth of Chongqing. Chongqing University.

Zhang, X. (2009). Dialectical Analysis on Use Rate of Energy in China and Economic Growth. Productivity Reseach, 6,25 . 